\title{
PENGARUH KELOMPOK REFERENSI TERHADAP KEPUTUSAN BERKUNJUNG DIKAWASAN WISATA KULINER PANTAI KOLO
}

\author{
Sri Ernawati ${ }^{1}$, Herry Nurdin ${ }^{2}$, Sulhaini ${ }^{3}$ \\ ${ }^{1}$ Sekolah Tinggi Ilmu Ekonomi (STIE) Bima, sriernawati.stiebima@gmail.com \\ ${ }^{2}$ Sekolah Tinggi Ilmu Ekonomi (STIE) Bima, herrynurdin.stiebima@gmail.com \\ ${ }^{3}$ Fakultas Ekonomi dan Bisnis Universitas Mataram, sulhaini@unram.ac.id
}

\begin{tabular}{ll|lll}
\hline Article history & \multicolumn{1}{l}{} \\
\hline Dikirim tanggal & $: 11 / 06 / 2021$ & Diterima tanggal & $:$ & $13 / 08 / 2021$ \\
Revisi pertama tanggal & $: 11 / 08 / 2021$ & Tersedia online tanggal & $:$ & $08 / 09 / 2021$ \\
\hline
\end{tabular}

\begin{abstract}
ABSTRAK
Penelitian ini bertujuan untuk mengetahui pengaruh kelompok referensi terhadap terhadap Keputusan Berkunjung dikawasan wisata kuliner pantai Kolo. Jenis penelitian yang digunakan yaitu Kuantitatif, lokasi penelitian di Kota Bima. Populasi dalam penelitian inin adalah semua konsumen yang pernah berkunjung dikawasan wisata kuliner pantai Kolo, sampel dalam penelitian ini berjumlah 100 orang dengan teknik purposive sampling. Instrumen penelitian menggunakan kuesioner dengan pengukuran skala likert Adapun jenis data yang digunakan dalam penelitian ini adalah data kuantitatif dengan sumber data penelitian yaitu data primer. Teknik pengumpulan data yaitu observasi, angket/koesioner dan studi pustaka. Analisis data menggunakan regresi linear sederhana. Hasil penelitian menunjukan semua kuesioner yang di gunakan valid dinama nilai $r$ hitung lebih besar dari $r$ table dan realibel dimana nilai Cronbach alpha $>0,600$. Penelitian ini dapat dinyatakan bahwa Kelompok Referensi berpengaruh terhadap Keputusan Berkunjung dikawasan wisata kuliner pantai Kolo, hal ini dapat dibuktikan dimana nilai t hitung lebih besar dari nilai $t$ tabel $(4,064>1,660)$ dan nilai signifikan 0,00 lebih kecil dari 0.05 ini berarti bahwa pengaruh yang ditimbulkan signifikan
\end{abstract}

Kata Kunci: Kelompok Referensi, Keputusan Berkunjung, Wisata Kuliner

\section{ABSTRACT}

This study aims to determine the influence of reference groups on the visit decision to the Kolo beach culinary tourism area. The type of research used is kuantative, the research location is in the City of Bima. The population in this study were all consumers who had visited the Kolo beach culinary tourism area, the sample in this study amounted to 100 people with purposive sampling technique. The research instrument uses a questionnaire with a Likert scale measurement. The type of data used in this study is quantitative data with research data sources, namely primary data. Data collection techniques are observation, questionnaires/questionnaires and literature study. Data analysis used simple linear regression. The results showed that all the questionnaires used were valid, where the calculated $r$ value was greater than the r table and reliable where the Cronbach alpha value was $>0.600$. This study can be stated that the Reference Group has an effect on the decision to visit the Kolo beach culinary tourism area, this can be proven where the t-count value is greater than the t-table value $(4,064>1.660)$ and $a$ significant value of 0.00 is smaller than 0.05. caused significant

Key Word: Reference Groups, Visit Decision, Culinary Tourism 


\section{Latar Belakang}

\section{PENDAHULUAN}

Kelompok referensi/acuan adalah individu atau kelompok nyata atau khayalan yang memiliki pengaruh evaluasi, aspirasi, bahkan perilaku terhadap orang lain. Kelompok acuan (yang paling berpengaruh terhadap konsumen) mempengaruhi orang lain melalui norma, informasi, dan melalui kebutuhan nilai ekspresif konsumen. Kelompok ini terdiri atas orang-orang yang mempunyai pandangan tertentu tentang bagaimana harus bertindak dalam suatu keadaan. Mereka sering dijadikan pedoman oleh konsumen dalam bertingkah laku. Kelompok referensi dapat berbentuk organisasi formal yang besar, terstruktur dengan baik, memiliki jadwal pertemuan rutin, dan karyawankaryawan yang tetap. Dilain pihak, kelompok acuan juga berbentuk kelompok kecil dan informal. Kelompok acuan terdiri dari orang-orang yang dikenal secara mendalam (seperti keluarga atau sahabat) atau orang-orang yang dikenal tanpa ada hubungan yang mendalam (klien) atau orang-orang yang dikagumi (tokoh atau artis). Karena orang cenderung membandingkan dirinya dengan orang lain yang memiliki kemiripan, mereka sering kali terpengaruh dengan mengetahui bagaimana orang lain menginginkan cara-cara yang mereka gunakan menjalani hidup sehari-hari. (Wina et all, 2015)

Keputusan pembelian merupakan kegiatan individu yang secara langsung terlibat dalam pengambilan keputusan untuk melakukan pembelian terhadap produk yang ditawarkan oleh penjual. Pengambilan keputusan merupakan suatu kegiatan individu yang secara langsung terlibat dalam mendapatkan dan mempergunakan barang yang ditawarkan. Informasi yang didapat oleh konsumen tersebut akan menjadi bahan pertimbangan sehingga pada akhirnya menjadi suatu keputusan untuk membeli produk yang sesuai dengan kebutuhannnya. Konsumen yang melakukan pembelian pada suatu produk didasarkan atas kebutuhan yang belum terpenuhi dan harus dipenuhi. (Oktavianingsih \& Setyawati, 2020) Kelompok referensi memiliki pengaruh yang cukup penting bagi seseorang dalam mengambil suatu keputusan pembelian. Terlebih halnya, ke-lompok primer seperti keluarga, kerabat ataupun rekan kerja. Kelompok referensi juga berperan dalam menentukan keputusan pembelian seseo-rang seperti hal nya memberi saran, pendapat serta rekomendasi terhadap pemilihan produk seseorang. (Nellyningsih \& Hidayat, 2020)

Penelitian yang ada telah menyelidiki dampak niat beli oleh reference group di berbagai situasi. Meskipun demikian, beberapa penelitian telah meneliti peran kelompok referensi (swasta dan publik) dalam niat pembelian tipe pembeli yang berbeda (utilitarian, nilai sosial, dan hedonis) dan tingkat keterlibatan produk (tinggi dan rendah). (Santosa\&Chayaningtyas, 2020). Beberapa faktor yang mempengaruhi keputusan pembelian yaitu (reference group), keluarga (family) sera peran dan status sosial (roles andstatus). pemilihan brand untuk setiap produknya dankesesuaian pemilihan brand tersebut secara signifikan sesuai dengan jenis kelompoknya Gap yang belum jelasnya apakah kelompok Referensi berpengaruh atau tidak terhadap keputusan pembelian (Anggriani et all, 2021). Kelompok referensi akan memberikan standar dan nilai yang akan mempengaruhi perilaku seseorang. Menurut penelitian dari (Wibowo \& Riyadi, 2017)di dalam junalnya yang menyatakan bahwa variabel kelompok referensi berpengaruh fositif dan signifikan keputusan pembelian ini kosmetik Korea di Surabaya sejalan dengan penelitian (Harnoto et al., 2018) kelompok referensi atau acuan bertanda positif terhadap keputusan pembelian. Berbeda dengan penelitian yang dilakukan Faadhilah, 2018) dalam penelitiannya secara parsial untuk beauty vlogge sebagai kelompok referensi tidak memiliki pengaruh terhadap keputusan pembelian kosmetik 
pada remaja perempuan pengguna kosmetik dan berbeda halnya dengan penelitian yang dilakukan oleh Sianturi, et al (2012), dimana hasil penelitiannya mengungkapkan bahwa tidak terdapat pengaruh secara parsial yang signifikan antara kelompok referensi terhadap keputusan pembelian. beberapa penelitian terdahulu yang peneliti angkat sebagai bahan pertimbangan untuk memperjelas bagaiamana pengaruh kelompok referensi dalam mempengaruhi keputusan konsumen, sesuai dengan arah penelitian yang ingin dicapai.

Perilaku individu dipengaruhi oleh kelompok dalam proses pembelian karena dalam kelompok atau komunitas terjadi suatu proses, pertama memberitahu dan mengusahakan agar individu menyadari adanya suatu produk atau merek khusus, kedua memberikan kesempatan pada individu untuk membandingkan pemikirannya sendiri dengan sikap dan perilaku kelompok, ketiga mempengaruhi individu untuk mengambil sikap dan perilaku yang sesuai dengan norma-norma kelompok, keempat membenarkan keputusan untuk memakai produkproduk yang sama dengan kelompok. (Anoraga\&iriani, 2014).

Pantai Kolo adalah salah satu wisata unggulan di Kota Bima. Selain pemandangannya, Pantai Kolo juga menyimpan potensi pesona bawah laut yang indah. Selain itu, Pantai Kolo memiliki kelebihan lain seperti menjadi pelabuhan altematif, tempat memancing, pusat tambak udang dan pegunungan disekitarnya yang bisa menjadi lahan pertanian yang menghasilkan buah. Banyak masyarakat yang berkunjung ke pantai Kolo selain ingin menikmati suasana pantai juga ingin menikmati wisata kuliner yang sajikan oleh masyarakat setempat disepanjang pesisir pantai. Rekomendasi berkunjung kesana banyak didapat dari keluarga, grup whatup, social media dan kelompok komunitas. Berdasarkan latar belakang masalah tersebut peneliti tertarik meneliti tentang pengaruh kelompok referensi terhadap terhadap Keputusan Berkunjung dikawasan wisata kuliner pantai Kolo

\section{Rumusan Masalah}

Berdasarkan latar belakang diatas maka rumusan masalah dalam penelitian ini adalah sebagai berikut: Apakah terdapat pengaruh kelompok referensi terhadap terhadap Keputusan Berkunjung dikawasan wisata kuliner pantai Kolo?

\section{Tujuan Penelitian}

Mengacu pada rumusan masalah tersebut di atas, maka tujuan dalam penelitian ini adalah Untuk mengetahui pengaruh kelompok referensi terhadap terhadap Keputusan Berkunjung dikawasan wisata kuliner pantai Kolo

\section{KAJIAN PUSTAKA}

\section{Kelompok Referensi}

Kelompok referensi/acuan adalah individu atau kelompok nyata atau khayalan yang memiliki pengaruh evaluasi, aspirasi, bahkan perilaku terhadap orang lain. Kelompok acuan (yang paling berpengaruh terhadap konsumen) mempengaruhi orang lain melalui norma, informasi, dan melalui kebutuhan nilai ekspresif konsumen. Kelompok ini terdiri atas orang-orang yang mempunyai pandangan tertentu tentang bagaimana harus bertindak dalam suatu keadaan. Mereka sering dijadikan pedoman oleh konsumen dalam bertingkah laku. (Wina et all, 2015)

Terdapat beberapa bentuk kelompok acuan yang dapat mempengaruhi konsumen dalam perilaku konsumsi, yaitu kelompok pertemanan, kelompok belanja, kelompok 
kerja, komunitas maya, dan kelompok aksi konsumen. Seorang pemberi opini ini adalah orang yang sering kali mampu mempengaruhi sikap atau perilaku orang lain. Opinion Leader memiliki sumber informasi yang berharga. Figur yang biasa menjadi opinion leader adalah artis, ahli pakar di bidang tertentu, orang awam (biasa), pimpinan perusahaan, dan karakter (Oentoro, 2010: 88).

\section{Keputusan Berkunjung}

Keputusan berkunjung bisa diartikan dengan keputusan pembelian, jadi dalam penelitian ini penelitian menggunakan keputusan pembelian untuk menggukur keputusan berkunjung konsumen. Peter dan Oslon (2013:163), berpendapat bahwa keputusan pembelian adalah proses evaluasi yang dilakukan oleh calon konsumen untuk mengkombinasikan pengetahuan yang dimiliki terhadap pilihan dua atau lebih alternatif produk dan memilih satu diantaranya.

Proses pembelian dimulai jauh sebelum pembelian sesungguhnya dan berlanjut dalam waktu yang lama setelah pembelian. Pemasar harus memusatkan perhatian pada keseluruhan proses pembelian yang dilakukan oleh konsumen. Menurut Kotler dan keller (2014:204) dalam proses keputusan pembelian, konsumen melewati lima tahap: pengenalan masalah, pecarian informasi, evaluasi alternatif, keputusan pembelian, dan perilaku pasca pembelian.

\section{Hubungan Antara Kelompok Referensi Dengan Keputusan Pembelian}

Kelompok referensi sebagai dasar perbandingan seseorang yang dapat mempengaruhi secara langsung dan tidak langsung, sehingga konsumen dapat melakukan keputusan pembelian yang dipengaruhi melalui interaksi dari kelompok tersebut. Sebelum seseorang memutuskan untuk membeli atau tidak maka harus diperhatikan terlebih dahulu ada tidaknya peranan orang lain dalam mempengaruhi keputusan pembelian tersebut. Seseorang berpotensi dipengaruhi oleh berbagai tipe orang maupun kelompok yang melakukan kontak dengan mereka atau yang mereka amati. Atas dasar inilah maka sangat perlu untuk memperhatikan kelompok acuan terhadap keputusan konsumen untuk membeli (Oktavianingsih\& Setyawati, 2020) Konsumen mempertimbangkan tingkat keterlibatan produk sebelum membeli produk yang mereka menggunakan kelompok referensi sebagai isyarat informasi, yang berkaitan dengan niat pembelian mereka. (Hoonsopon \& Puriwat, 2016)

\section{Hipotesis Penelitian}

Ha: Kelompok Referensi berpengaruh terhadap Keputusan Berkunjung dikawasan wisata kuliner pantai Kolo

Ho: Kelompok Referensi tidak berpengaruh terhadap Keputusan Berkunjung dikawasan wisata kuliner pantai Kolo

\section{METODE PENELITIAN}

Jenis penelitian yang digunakan dalam penelitian ini adalah jenis penelitian kuantitatif. jenis penelitian ini digunakan untuk mengetahui pengaruh kelompok referensi terhadap terhadap Keputusan Berkunjung dikawasan wisata kuliner pantai Kolo.Penelitian ini dilakukan di Kota Bima karena lokasi pantai kolo berada di kawasan Kelurahan kolo Kecamatan Asakota. Populasi adalah wilayah generalisasi yang terdiri atas obyek dan subyek yang mempunyai kualitas dan karakteristik tertentu yang ditetapkan oleh peneliti untuk dipelajari dan kemudian ditarik kesimpulannya 
(Sugiyono, 2016). Populasi yang digunakan adalah seluruh masyarakat Kota Bima yang pernah berkunjung ke kawasan kuliner yang berada di pantai Kolo dan jumlahnya tidak diketahui secara pasti (unknown population), oleh karena itu, jumlah sampel yang diambil adalah sebanyak 100 orang. Sedangkan Teknik pengambilan sampel yang digunakan adalah purposive sampling, yaitu pemilihan sampel berdasarkan pada karakteristik tertentu yang dianggap mempunyai sangkut pautnyadengan karakteristik populasi yang sudah diketahui sebelumnya yaitu sesuai dengan kriteria sampel penelitian.

Metode pengumpulan data yang digunakan dalam penelitian ini adalah metode sampel survey dengan penyebaran quesioner online pada masyarakat Kota Bima yang pernah berkunjung ke kawasan kuliner pantai Kolo, observasi dan studi pustaka. Menurut (Nazir, 2013), sampel survey adalah suatu prosedur yang mana hanya sebagian dari populasi saja yang diambil untuk menentukan sampel yang diharapkan dapat mewakili populasi secara keseluruhan guna memperoleh gambaran yang cukup representatif. Pengukuran varibel penelitian dalam penelitian ini, setiap variabel akan diukur dengan menggunakan skor yang mengacu pada penggunaan skala likert. Skala likert digunakan untuk mengukur sikap, pendapat, dan persepsi seseorang atau sekelompok orang tentang fenomena sosial (Sugiyono, 2016). Dalam memberikan pembobotan padamasing-masing variabel diberikan pilihan jawaban Sangat Setuju (SS) yang diberi skor 5, Setuju (S) yang diber skor 4, Netral $(\mathrm{N})$ yang diberi skor 3, Tidak Setuju (TS) yang diberi skor 2, dan Sangat Tidak Setuju (STS) yang diberi skor 1.

Jenis data yang digunakan dalam penelitian ini adalah kuantitatif. Data kuantitatif adalah data yang berupa angka-angka yang dapat dihitung dan diukur, data kuantitatif ini berasal dari jawaban angket yang diberi skor kemudian dihitung dengan alat analisis yang digunakan. Sumber data yang digunakan dalam penelitian ini adalah data primer yaitu data yang berasal dari hasil qusioner yang dibagikan kepada responden.

Setelah semua data baik dari sumber primer maupun sekunder telah terkumpul maka dapat dilakukan analisis data. Analisis data terdiri dari beberapa tahapan, dimulai dari tahap pengelompokkan data, tabulasi data, penyajian data, hingga perhitungan untuk menguji hipotesis dan menjawab masalah penelitian. Pengujian Data menggunakan uji validitas, uji Reliabilitas, Analisis regresi linier sederhana dengan persamaan $\mathrm{Y}=\mathrm{a}+\mathrm{b}+\mathrm{x}+\mathrm{e}$, Analisis korelasi, Koefisien determinasi dan uji signifikasi (Uji t-statistik)

\section{HASIL DAN PEMBAHASAN}

\section{Karakteristik responden}

Dalam penelitian ini kuesioner di sebarkan secara online mengginggat penelitian ini dilakukan disaat pandemic covid 19. Gambaran umum responden dalam penelitian ini dapat dilihat dari karakte-ristik responden yang meliputi jenis kelamin, pendidikan, dan pekerjaan. Gambaran umum mengenai profil responden dalam penelitian ini dapat dilihat dalam Tabel 1 berikut ini. 
Tabel 1.

Karakteristik Responden

\begin{tabular}{llcc}
\hline Karakteristik & \multicolumn{1}{c}{ Kriteria } & $\begin{array}{c}\text { Jumlah } \\
\text { Responden }\end{array}$ & Persentase \\
\hline Jenis Kelamin & Perempuan & 78 & 78 \\
& Laki-laki & 22 & 22 \\
Pendidikan & Strata 2 (S2) & 9 & 9 \\
& Strata satu (S1) & 45 & 45 \\
& Ahli Madya (D) & 31 & 31 \\
\multirow{5}{*}{ Pekerjaan } & SMA (Sekolah Menengah atas) & 15 & 15 \\
& ASN ( Aparatur Sipil Negara) & 42 & 42 \\
& Pegawai Swasta & 29 & 29 \\
& Wiraswasta & 15 & 15 \\
& IRT (Ibu Rumah Tangga) & 14 & 14 \\
\hline
\end{tabular}

$\mathrm{n}=100$

Dari diatas tabel 1 menunjukan dari karakteristik jenis kelamin perempuan lebih mendonimasi dengan 78 persen, dari pendididkan strata satu (S1) lebih dominan sebesar 45 persen dan karakteristik pekerjaan ASN (Aparatur Sipil Negara) dengan perolehan 42 persen lebih besar di banding yang lain.

\section{Hasil Uji Validitas dan Uji Reliabilitas}

a. Hasil Uji Validitas

Tabel 2.

Hasil Uji Validitas

\begin{tabular}{ccccc}
\hline Variabel & Item & r hit & r tab & Keterangan \\
\hline \multirow{4}{*}{ Kelompok Referensi } & 1 & 0,439 & 0,300 & Valid \\
& 2 & 0,703 & 0,300 & Valid \\
& 3 & 0,615 & 0,300 & Valid \\
& 4 & 0,508 & 0,300 & Valid \\
& 5 & 0,653 & 0,300 & Valid \\
& 6 & 0,429 & 0,300 & Valid \\
& 7 & 0,586 & 0,300 & Valid \\
& 8 & 0,752 & 0,300 & Valid \\
& 1 & 0,465 & 0,300 & Valid \\
& 2 & 0,580 & 0,300 & Valid \\
& 3 & 0,554 & 0,300 & Valid \\
& 4 & 0,519 & 0,300 & Valid \\
& 5 & 0,611 & 0,300 & Valid \\
& 6 & 0,593 & 0,300 & Valid \\
& 7 & 0,515 & 0,300 & Valid \\
& 8 & 0,568 & 0,300 & Valid \\
& 9 & 0,483 & 0,300 & Valid \\
\hline
\end{tabular}

Sumber Data: data Primer diolah SPSS 20,00

Berdasarkan tabel 1 di atas, hasil pengujian validitas variabel Kelompok referensi dan keputusan berkunjung dapat dikatakan valid pada Corrected item-total 
correlation $>0,300$. Hasil pengujian validitas ini menunjukkan bahwa pernyataan kuesioner dalam penelitian ini valid.

b. Hasil Uji Reliabilitas

Tabel 3.

Hasil Uji Reliabilitas

\begin{tabular}{lccc}
\hline \multicolumn{1}{c}{ Variabel dan Indikator } & $\begin{array}{c}\text { Cronbach's } \\
\text { Alpha }\end{array}$ & $\begin{array}{c}\text { Standar } \\
\text { Reliabilitas }\end{array}$ & Keterangan \\
\hline Variabel Kelompok Rujukan $(\mathrm{X})$ & 0,733 & $>0,600$ & Reliabel \\
Variabel Keputusan Berkunjung (Y) & 0,700 & $>0,600$ & Reliabel \\
\hline
\end{tabular}

Sumber Data: data Primer diolah SPSS 20,00

Hasil pengujian penelitian menggunakan pengukuran ini dapat dikatakan reliabel pada Cronbach alpha $>0,600$. Hasil pengujian reliabilitas ini menunjukkan bahwa pernyataan quesioner dalam penelitian ini reliable

\section{Hasil uji regresi linear sederhana}

Tabel 4.

Hasil uji regresi linear sederhana

\begin{tabular}{|c|c|c|c|c|c|c|}
\hline & \multirow[t]{2}{*}{ Model } & \multicolumn{2}{|c|}{ Unstandardized Coefficients } & \multirow{2}{*}{$\begin{array}{l}\text { Standardized } \\
\text { Coefficients } \\
\text { Beta }\end{array}$} & \multirow[t]{2}{*}{$\mathbf{t}$} & \multirow[t]{2}{*}{ Sig. } \\
\hline & & B & Std. Error & & & \\
\hline \multirow{2}{*}{1} & (Constant) & 25.880 & 3.270 & & 7.916 & .000 \\
\hline & Kelompok Referensi & .378 & .093 & .380 & 4.064 & .000 \\
\hline
\end{tabular}

a. Dependent Variable: Keputusan Berkunjung

Sumber Data: data Primer diolah SPSS 20,00

Persamaan regresi linier sederhana:

$$
\mathrm{Y}=25.880+0,378 \mathrm{X}
$$

Konstantan $\quad=25.880$ artinya jika kelompok referensi konstan atau sama dengan nol maka Keputusan Berkunjung dikawasan wisata kuliner pantai Kolo akan naik sebesar 25.880.

Koefisien variable $\mathrm{b}=0,378$ artinya jika kelompok referensi naik sebesar satu satuan maka Keputusan Berkunjung dikawasan wisata kuliner pantai Kolo. akan naik sebesar 0, 378 atau sebaliknya.

\section{Hasil uji Korelasi}

Tabel 5.

Hasil Uji korelasi dan Determinasi

\begin{tabular}{lrrrr}
\hline Model & R & R Square & \multicolumn{1}{c}{$\begin{array}{c}\text { Adjusted R } \\
\text { Square }\end{array}$} & \multicolumn{2}{c}{$\begin{array}{c}\text { Std. Error of the } \\
\text { Estimate }\end{array}$} \\
\hline 1 & $.380^{\mathrm{a}}$ & .144 & .136 & 2.76666 \\
\hline
\end{tabular}

a. Predictors: (Constant), Kelompok Referensi

Sumber Data: data Primer diolah SPSS 20,00

Nilai koefisien kolerasi yaitu sebesar 0, 380.Artinya tingkat keeratan hubungan antara kelompok rujukan terhadap Keputusan Berkunjung Rendah sebesar 0, 380. 


\section{Hasil uji Determinasi}

Dari data diatas, dapat diketahui bahwa koefisien determinasi (R Square) yang diperoleh sebesar $14,40 \%$ sedangkan sisanya $85,60 \%$ dipengaruhi oleh faktor-faktor lain yang tidak diteliti dalam penelitian

\section{Hasil Uji t}

Tabel 6.

Hasil Uji t

\begin{tabular}{llrrrrr}
\hline \multirow{2}{*}{ Model } & \multicolumn{2}{c}{$\begin{array}{c}\text { Unstandardized } \\
\text { Coefficients }\end{array}$} & $\begin{array}{c}\text { Standardized } \\
\text { Coefficients }\end{array}$ & \multirow{2}{*}{ t } & \multirow{2}{*}{ Sig. } \\
\cline { 2 - 4 } & \multicolumn{1}{c}{ B } & Std. Error & \multicolumn{1}{c}{ Beta } & & \\
\hline \multirow{2}{*}{1} & (Constant) & 25.880 & 3.270 & & 7.916 & .000 \\
& Kelompok Referensi & .378 & .093 & .380 & 4.064 & .000 \\
\hline
\end{tabular}

a. Dependent Variable: Keputusan Berkunjung

Sumber Data: data Primer diolah SPSS 20,00

Hasil statistik uji t untuk variabel kelompok rujukan memperoleh nilai thitung sebesar 4,064 dengan nilai ttabel sebesar 1,660, dimana ( $\mathrm{t}$ hit $>\mathrm{t}$ tab, 4,064 > 1,660), maka hipotesis Ha yang menyatakan bahwa kelompok referensi berpengaruh terhadap keputusan berkunjung dikawasan wisata kuliner pantai Kolo (Diterima). Penelitian ini sejalan dengan penelitian yang dilakukan (Fitria \& Artanti, 2020) yang menyatakan bahwa kelompok referensi berpengaruh signifikan terhadap keputusan pembelian

\section{Pembahasan}

Pariwisata dapat mendukung suatu daerah dapat dikenal oleh masyarakat luas dengan ciri khas yang dimiliki daerah tersebut. Dimana keseluruhan elemen yang terdapat dalam pariwisata seperti wisatawan, daerah tujuan wisata, perjalanan, industri dan lain sebagainya yang merupakan kegiatan pariwisata. Keadaan di Pantai Kolo sebagai destinasi wisata bahari yang ada di Kota Bima juga memberikan elemen industri yaitu usaha kuliner yang dikelolah oleh masyarakat setempat. Wisata kuliner ini terus berkembang seiring dengan perkembangan wisata pantai kolo yang sudah menjadi kawasan wisata prioritas Kota Bima.

Wisatawan akan tertarik untuk mengunjungi suatu obyek wisata setelah mendapatkan informasi dan rekomendasi dari individu atau kelompok yang dapat memepengaruhi keputusannnya untuk bertindak. Selai melihat apa saja yang ditawarkan atau disediakan oleh suatu obyek wisata. Kaitanya dengan pariwisata, kunjungan wisatawan ke suatu daerah bisa saja karena masukan atau saran yang berasal dari kelompok referensi wisatawan tersebut. Dimana kelompok referensi memberikan saran mengenai layak tidaknya suatu tempat untuk dikunjungi berdasarkan pembelian atau kunjungan yang pernah dilakukan. Oleh karena itu penting untuk mengetahui peranan reference group dalam mempengaruhi keputusan berkunjung wisatawan

\section{Kesimpulan}

\section{KESIMPULAN DAN SARAN}

Kelompok Referensi berpengaruh terhadap Keputusan Berkunjung dikawasan wisata kuliner pantai Kolo, dimana Kawasan pantai kolo dijadikan destinasi wisata unggulan yang ada di Kota Bima, pengembangan juga mendapat perhatian khusus dari Dinas pariwisata Kota Bima, khusus untuk wisata bahari dan kuliner ikan bakar yang dilengakapi dengan sambal khas bima. Dengan adanya wisata kuliner yang ada di pantai kolo menjadi daya tarik tersendiri bagi wisatawan. kunjungan wisatawan meningkat 
kerena selain menikmati wisata bahari, wisatawan juga menikmati wisata kuliner, sehingga pendapatan masyarakat menjadi meningkat, adanya sewa parker dan nelayan yang berada di kelurahan Kolo dan sekitarnya menjual hasil tangkapannnya selain di pasar juga menjual di pengelola kuliner yang ada dipanjang pantai kolo. Jadi dengan adanya kawasan kuliner di pantai kolo bisa mendatangkan multiplayer efek bagi masyarakat Kota Bima pada umumnya dan khususnya masyarakat kelurahan Kolo dan sekitarnya.

\section{Saran}

Pantai kolo menyuguhkan pemandangan yang indah, selain hamparan pantai yang luas, juga dari arah pantai kolo kita dapat melihat pulau kambing, pergunungan soromandi dan donggo yang menambah keindahan pemandangan pantai kolo. Mengingat potensi yang sangat besar yang dimiliki pantai kolo, maka pemerintah harus segera mengambil langkan strategis untuk pengembanagan kawasan pantai kolo seperti perbaikan sarana dan prasarana akses ke pantai kolo, menambah fasilitas seperti baruga disepanjang pantai kolo, selalu diawasi kebersihan pantai, agar bisa dijadikan ikon wisata di Kota Bima sehingga bisa meningkatkan PAD pemerintah Kota Bima.

\section{REFERENSI}

Anggriani Melia, Fitriani \& Sanjaya F Vicky, (2020). Pengaruh Kelompok Referensi, Media Sosial, Word Of Mouth Terhadap Keputusan Pembelian Pada Generasi Milenial. Jurnal Ekonomak Vol. 6 No. 3, Hal 1-8

Anoraga Jalasena Bintang, Iriani Setyi Sri, (2014). Pengaruh Gaya Hidup Dan Kelompok Acuan Terhadap Keputusan Pembelian Smartphone Merek Samsung Galaxy. Bintang Jalasena Anoraga, Sri Setyo Iriani. Bisma (Jurnal Bisnis dan Manajemen, Vol 6 No. 2. Hal. 139-147

Faadhilah, F, Novia. (2018). Pengaruh Gaya Hidup Konsumtif Dan Beauty Vlogger Sebagai Kelompok Referensi Terhadap Keputusan Pembelian Kosmetik (Studi Pada Remaja Perempuan Pengguna Kosmetik Korea Di Surabaya). Jurnal Ilmu Manajemen (JIM), 7(1), 133-142.

Fitria Sarah, Artanti Yessy, (2020). Pengaruh Religiusitas dan Kelompok Referensi Terhadap Keputusan Pembelian. BISNIS: Jurnal Bisnis dan Manajemen Islam. Volume 8, Nomor 1, Hal 37-47. http://journal.iainkudus.ac.id/index.php/bisnis/ index, DOI: 10.21043/bisnis.v8i1.6732

Ghozali, Imam. (2018). Aplikasi Analisis Multivariate dengan Program IBM SPSS 25. Badan Penerbit Universitas Diponegoro: Semarang

Harnoto, T., Budi, Y., \& Silintowe, R. (2018). Keputusan Pembelian Smartphone Oleh Mahasiswa: Kelompok Acuan Atau Gaya Hidup. Journal Ilmu Komunikasi, 30(2), 181-197. https://ojs.uajy.ac.id/index.php/modus/article/download/1708/ 1188

Hoonsopon, D., \& Puriwat, W. (2016). The effect of reference groups on purchase intention: Evidence in distinct types of shoppers and product involvement. Australasian Marketing Journal, 24(2), 157-164. https://doi.org/10.1016/ j.ausmj.2016.05.001 
Kotler dan Keller. (2014). Manajemen Pemasaran. Jilid I. Edisi Ke 13. Jakarta: Erlangga.

Nazir, Moh. (2013). Metode Penelitian. Bogor: Ghalia Indonesia

Nellyaningsih, Hidayat Rahmat, (2019). Analisis Pengaruh Kelompok Referensi Terhadap Keputusan Pembelian Jasa Asuransi. Jurnal AKRAB JUARA Vol. 4 No. 4, Hal 144-155

Oetoro, S., Parengkuan, E. (2012). Smart Eating. Jakarta: Gramedia Pustaka Utama.

Oktavianingsih Isnaeni \& Setyawati Abrilia Hariri, (2020). Pengaruh Kelompok Acuan, Gaya Hidup dan Citra Merek terhadap keputusan Pembelian Helm Merek INK. JIMMBA (Jurnal ilmiah mahasiswa manajemen, bisnis dan akuntasi). Vol. 2 No. 4, Hal 619-630

Peter, J Paul and Jerry C Olson. (2013). Perilaku Konsumen dan Strategi Pemasaran Terjemahan oleh Diah Tantri Dwiandani Edisi Kesembilan Jilid 1. Jakarta: Erlangga.

Santosa Deana Allicia \& Chayaningtya Dwi Indyra, (2020). Pengaruh Personal Selling Dan Reference Group Terhadap Keputusan Pembelian Konsumen. Jurnal Manajemen. Vol 6 No. 2, Hal 67-73. http://jurnal.unsil.ac.id/index.php/jem

Sianturi evanina, Erida, Nifita Titi Ade. (2012). Pengaruh Kelompok Referensi dan Gaya Hidup terhadap Keputusan Menggunakan BlackBerry. Vol 1 N0. 2. ISSN: 2302-4682.

Sugiyono. (2016). Metode Penelitian Kuantitatif, Kualitatif dan R\&D. Bandung: Alfabeta.

Wilna Elsa, Lubis Nawazirul Prabawani Bulan, (2015). Pengaruh Promosi dan Kelompok Referensi Terhadap Keputusan Menabung Nasabah Tabungan Simpedes Pada PT. Bank Rakyat Indonesia (Persero) Tbk Kantor Cabang Brigjen Sudiarto Semarang. JIAB (Jurnal Administrasi Bisnis), Vol. 4 No. 2. https://ejournal3.undip.ac.id/index.php/jiab/index

Wibowo, A. F., \& Riyadi, E. S. hendro. (2017). Pengaruh Gaya Hidup, Prestise Dan Kelompok Referensi Terhadap Keputusan Pembelian (Studi Pada Konsumen Taiwan Tea House Semarang). Prosiding Seminar Nasional Riset Manajemen \& Bisnis. 